\title{
MENINGKATKAN PENDIDIKAN DAN PEMBINAAN PERILAKU HIDUP BERSIH DAN SEHAT MASYARAKAT
}

\author{
Fauzi Syamsuar ${ }^{1}$, Akbar Marfu Alam, Rahayu Indah Sari ${ }^{2}$ \\ fauzi.syamsuar@uika-bogor.ac.id \\ Dosen Fakultas Keguruan dan Ilmu Pendidikan ${ }^{1}$, Mahasiswa KKN Kelompok 61 Tahun \\ $2018^{2}$
}

\begin{abstract}
ABSTRAK
Kuliah Kerja Nyata (KKN) merupakan kegiatan dharma bakti mahasiswa. Sebagai orang yang telah mengenyam pendidikan di bangku kuliah, mahasiswa yang telah mendapat ilmu seyogianya mempraktikkan ilmunya ke masyarakat. Sasaran kegiatan adalah warga desa Wangun Jaya, Leuwisadeng, Bogor, Jawa Barat. Mahasiswa yang terjun dalam pelaksanaan KKN sebanyak 13 mahasiswa dari berbagai fakultas. Hasil kegiatan KKN menunjukan bahwa di Kp. Cisaranten II, $45 \%$, anak putus sekolah atau tidak menjalankan program wajib belajar dari pemerintah yakni 12 tahun. Banyak faktor yang mempengaruhi salah satunya adalah masalah ekonomi yang membuat anak putus sekolah. Infrastruktur sekolah yang kurang memadai dalam kegiatan belajar mengajar juga menjadi faktor. UU No 36 Tahun 2009 pasal 4 disebutkan bahwa setiap warga berhak atas kesehatan dan berhak memperoleh pelayanan kesehatan yang aman, bermutu, dan terjangkau (Ps.5). Perilaku Hidup Bersih dan Sehat (PHBS) adalah program pemerintah yang diluncurkan dimana bertujuan untuk mengubah perilaku masyarakat yang tidak sehat agar menjadi sehat. Kesimpulan dari kegiatan ini adalah bahwa semua siswa di PAUD Cahaya 01 Cisaranten II, desa Wangun Jaya memiliki pengetahuan, sikap dan perilaku yang baik tentang Perilaku Hidup Bersih dan Sehat sekolah. Diharapkan bahwa sekolah tetap terus mengajarkan tentang Perilaku Hidup Bersih dan Sehat (PHBS) sekolah kepada seluruh siswa.
\end{abstract}

Kata kunci: KKN, Pendidikan, PHBS.

\section{PENDAHULUAN}

Kuliah Kerja Nyata $($ KKN) adalah salah satu program perguruan tinggi untuk menerapkan Tridarma perguruan tinggi, yaitu melaksanakan pendidikan dan pengajaran, penelitian, dan pengabdian kepada masyarakat. Ranah pendidikan, pengajaran, dan penelitian sudah didapatkan oleh mahasiswa di kelas-kelas dan bangku kuliah. Sedangkan untuk pengabdian masyarakat masih membutuhkan ruang-ruang khusus, salah satunya adalah dengan adanya KKN. Kuliah Kerja Nyata mempunyai empat kelompok sasaran, yaitu mahasiswa, masyarakat, pemerintah daerah, dan perguruan tinggi. Bagi mahasiswa Kuliah Kerja Nyata mempunyai sasaran untuk membina mahasiswa agar menjadi motivator dan inovator. Sasaran bagi masyarakat dan Pemda adalah untuk memperoleh bantuan pemikiran, tenaga, serta IPTEK dalam merencanakan dan melaksanakan pembangunan. Sasaran bagi perguruan tinggi adalah untuk memperoleh 
umpan balik sebagai hasil pengintegrasian mahasiswa dalam masyarakat, sehingga kurikulum perguruan tinggi dapat disesuaikan dengan kondisi masyarakat yang diwakili oleh PEMDA yang terkait.

Melalui KKN ini, kami mahasiswa dari Universitas Ibn Khaldun, berupaya untuk melaksanakan program pengabdian masyarakat yang terbentuk dalam sebuah program Meningkatkan Pendidikan di desa Wangun Jaya, Leuwisadeng Kabupaten Bogor. Program meningkatkan mutu pendidikan ini tidak hanya memberikakan pembelajaran dan pengetahuan tentang membaca, menulis dan berhitung, tapi juga memberikan wawasan dan pengetahuan fungsional tentang kewirausahaan serta keterampilan tepat guna yang dapat digunakan oleh masyarakat dalam peningkatan kualitas hidupnya.

Dalam kondisi realnya di desa Wangun Jaya, $45 \%$, anak putus sekolah, tidak menjalankan program wajib belajar dari pemerintah yakni 12 tahun. Banyak faktor yang mempengaruhi salah satunya adalah masalah ekonomi yang membuat anak putus sekolah. Juga paradigma yang menyatakan bahwa pendidikan agama itu lebih penting dari pada pendidikan umum (sekolah). Padahal, sejatinya keduanya harus balance antara pendidikan agama dengan pendidikan sekolah yang mana satu dengan yang lainnya saling melengkapi dan membutuhkan antara satu dengan yang lainnya.

Infrastruktur pendidikan di desa Wangun Jaya, kurang menunjang dalam kegiatan belajar mengajar di sekolah. Di mana dalam penelitian kami, banyak infrastruktur sekolah yang rusak dan kurang memadai juga perpustakaan atau taman baca yang belum memadai untuk merangsang siswa untuk rajin membaca.
Untuk itu, salah satu program kami adalah revitalisasi taman baca dengan memperindah dan menambah atribut atribut dan buku - buku pelajaran agar menarik minat siswa untuk senantiasa membaca. Karena sejatinya membaca adalah awal dari suatu ilmu.

Kesehatan merupakan anugerah terbesar yang diberikan oleh Tuhan YME kepada hamba-Nya. Tanpa kesehatan, hidup tak akan berarti. Namun terkadang orang lupa akan nikmat kesehatan yang dimilikinya karena terhanyut akan mimpimimpi indahnya.

Dalam hal ini, kami memiliki program perilaku hidup bersih dan sehat (PHBS). Perilaku hidup bersih dan sehat seseorang sangat berkaitan dengan peningkatkan kesehatan individu, keluarga, masyarakat dan lingkungannya. Secara umum, warga Kp. Cisaranten II desa Wangun Jaya belum menerapkan perilaku hidup bersih dan sehat. Hal ini berdasarkan penelitian masih banyaknya warga yang buang sampah sembarang di kali, yang menyebabkan air tercemar sehingga menyebabkan banyaknya penyakit.

Dalam penerapan PHBS ini, kami melakukan penelitian di PAUD Cahaya 01. Yang mana penelitian menunjukan indikator yang baik terhdap perilaku hidup bersih dan sehat, Menurut Eska dalam Jurnal Abdi Dosen Pemberdayaan kesehatan merupakan kegiatan penambahan pengetahuan yang diperuntukan bagi masyarakat melalui penyebaran pesan..

Salah satu tujuan kami melakukan penelitian terhadap siswa PAUD Cahaya 01 adalah menanamkan pola hidup bersih dan sehat sejak dini agar terbiasa hingga dewasa kelak. Juga, menerapkan upaya preventif terhadap orang tua siswa, yang mana ketika anaknya sudah terbiasa 
dengan perilaku hidup bersih dan sehat, maka orang tua akan mengikuti bahkan akan menimbulkan rasa malu apabila masih belum menerapkan perilaku hidup bersih dan sehat dalam keluarganya.

\section{Demografi}

\section{Letak Geografis}

Luas wilayah Desa Wangun Jaya 301,76 Ha, yang terdiri dari $11 \mathrm{RW}, 40 \mathrm{RT}$ dan 5 Dusun. Yakni dusun I, II, III, IV, dan V.

\section{Topografi}

Desa Wangun Jaya merupaka desa yang berada didaerah dataran tinggi / pegunungan. Dengan ketinggian +- 110 501 meter di atas permukaan laut (mdpl). Sebagian besar wilayah desa adalah lahan pertanian /sawah/ tegalan dengan permukaan tanah datar $15 \%$, berbukit bukit $50 \%$ dan lereng $35 \%$. Suhu rata - rata harian mencapai $15-20 \mathrm{C}$ dan curah hujan rata - rata $2500-3000 \mathrm{Mm} /$ tahun. dengan batas - batas wilayah sebagai berikut:

\begin{tabular}{|c|c|}
\hline Batas & Desa \\
\hline Sebelah Utara & Babakan Sadeng \\
\hline Sebelah Selatan & $\begin{array}{c}\text { Tanah } \\
\text { Kehutanan }\end{array}$ \\
\hline Sebelah Timur & Sadeng Kolot \\
\hline Sebelah Barat & $\begin{array}{c}\text { Sukaluyu, Kec. } \\
\text { Nanggung }\end{array}$ \\
\hline
\end{tabular}

\section{Keadaan Sosial}

\section{Kependudukan}

Penduduk di Desa Wangun Jaya sebagian besar bermata pencaharian sebagai petani dan buruh tani. Selain itu, ada beberapa masyarakat yang bekerja sebagai pedagang, sopir, dan ada yang bekerja sebagai Pegawai Negeri Sipil (PNS) dan pegawai di lembaga-lembaga pemerintahan.

\section{Kesehatan}

Tenaga kesehatan di Desa Wangun Jaya terdiri dari dokter 1 orang, perawat 0 orang, bidan desa 1 orang.

\begin{tabular}{|l|l|l|c|}
\hline No & \multicolumn{2}{|l|}{ Tenaga Kesehatan } & Jumlah \\
\hline \multirow{4}{*}{1.} & \multirow{4}{*}{ Medis } & $\begin{array}{l}\text { Dokter } \\
\text { Umum }\end{array}$ & 1 \\
\cline { 3 - 4 } & & $\begin{array}{l}\text { Dokter } \\
\text { Spesialis }\end{array}$ & \\
\hline \multirow{2}{*}{2.} & \multirow{2}{*}{ Perawat } & Bidan & 1 \\
\cline { 3 - 4 } & & Perawat & \\
\hline \multirow{4}{*}{3.} & \multirow{3}{*}{$\begin{array}{l}\text { Partisipasi } \\
\text { Masyarakat }\end{array}$} & Dukun Bayi & 3 \\
\cline { 3 - 4 } & & Posyandu & 4 \\
\cline { 3 - 4 } & & Poskesdes & 1 \\
\cline { 3 - 4 } & & Desa Siaga & 1 \\
\cline { 3 - 4 } & & &
\end{tabular}




\section{METODE PENGABDIAN}

Tahapan pelaksanaan untuk kegiatan ini sebagaimana terlihat pada bagan berikut:

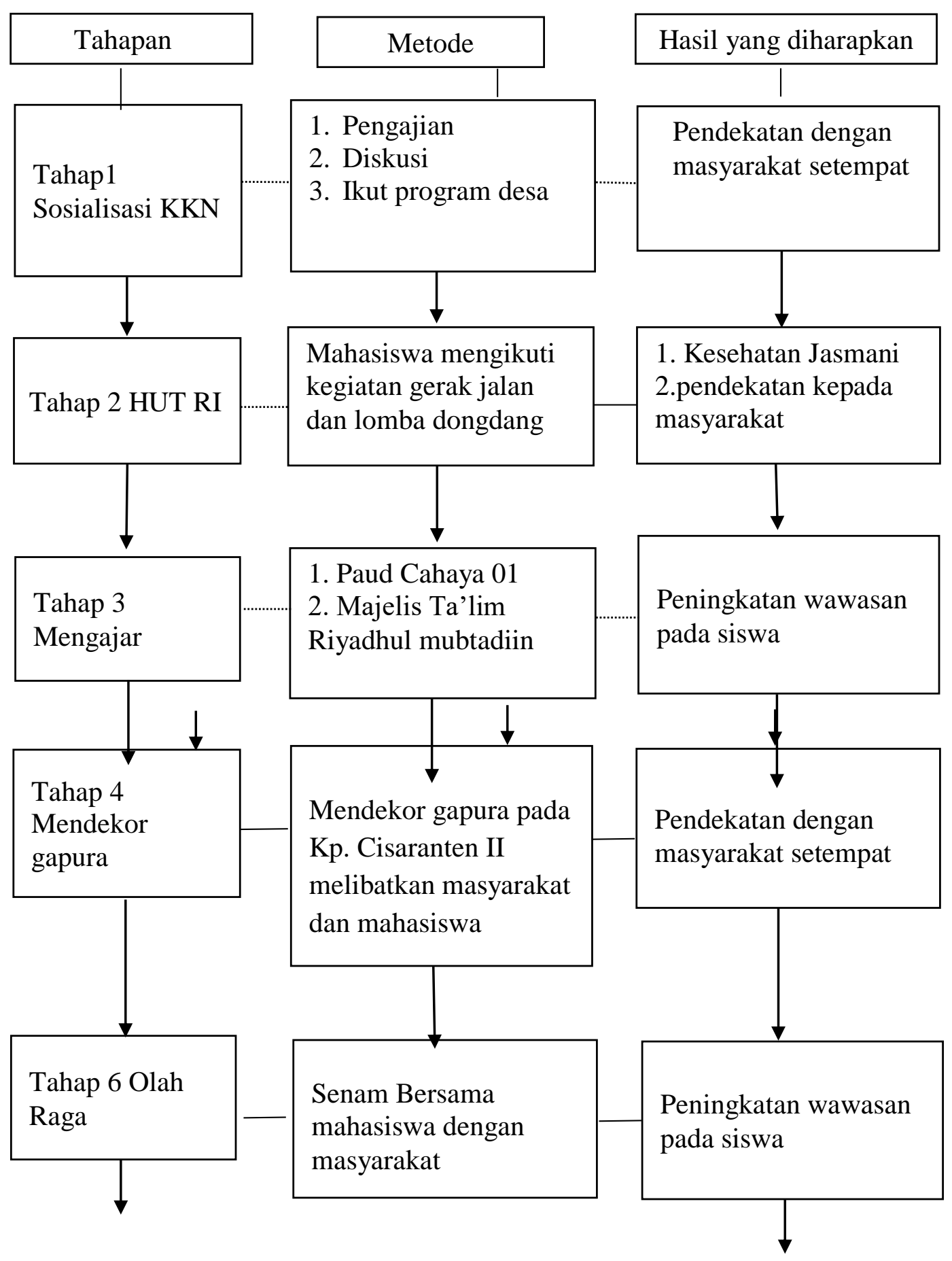




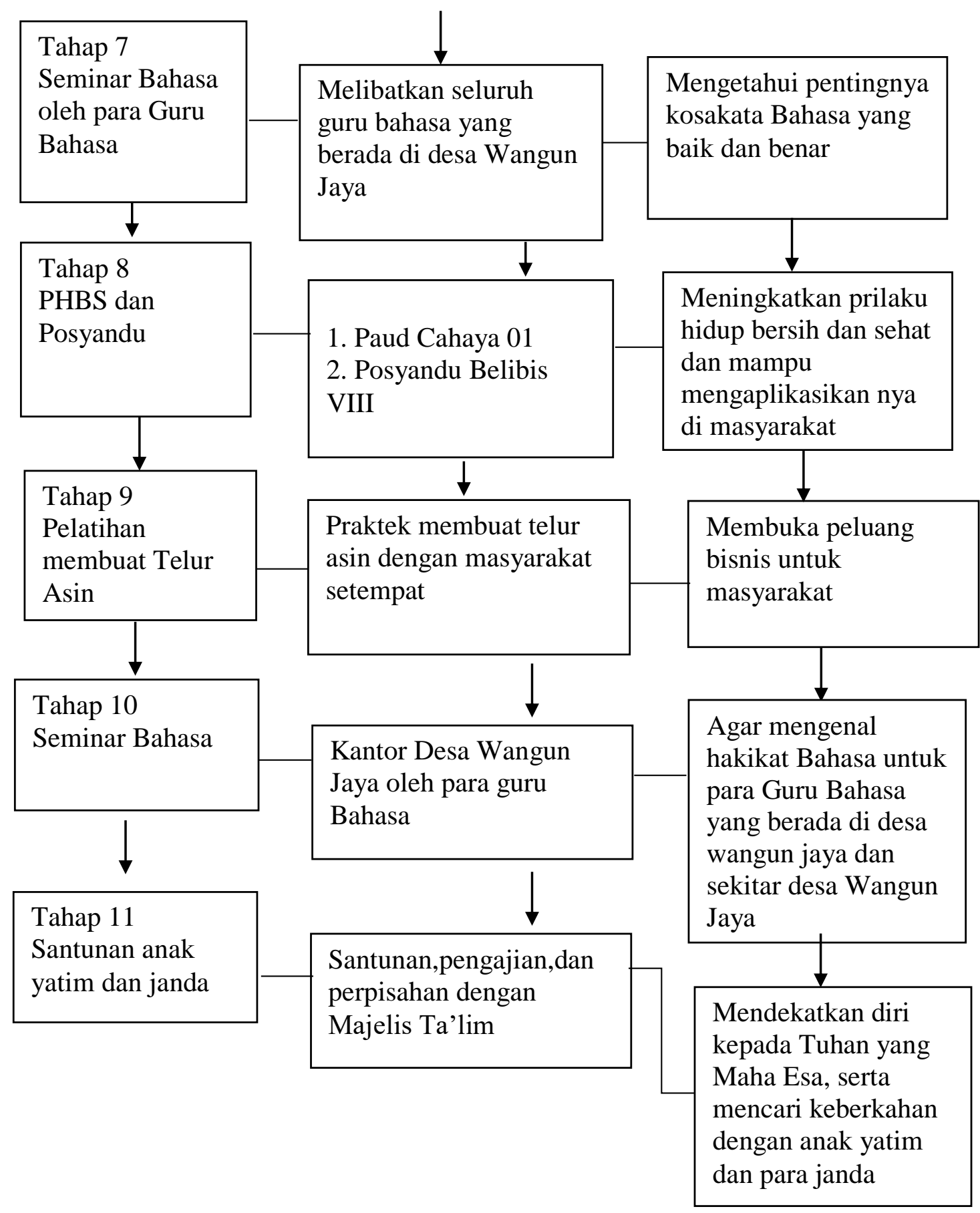


Tabel Jadwal Program Kerja

\begin{tabular}{|c|c|c|c|c|c|c|}
\hline \multirow[b]{2}{*}{ No } & \multirow[b]{2}{*}{ Program Kerja } & \multicolumn{4}{|c|}{ Agustus } & September \\
\hline & & $\begin{array}{l}\text { Minggu } \\
\text { II }\end{array}$ & $\begin{array}{l}\text { Minggu } \\
\text { III }\end{array}$ & $\begin{array}{l}\text { Minggu } \\
\text { IV }\end{array}$ & $\begin{array}{l}\text { Minggu } \\
\mathrm{V}\end{array}$ & $\begin{array}{l}\text { Minggu } \\
\text { I }\end{array}$ \\
\hline 1 & Sosialisasi Program KKN & & & & & \\
\hline 2 & Dekor Gapura & & & & & \\
\hline 3 & Pengajian Rutin & & & & & \\
\hline 4 & Ngajar di Paud & & & & & \\
\hline 5 & Gotong Royong & & & & & \\
\hline 6 & $\begin{array}{l}\text { ikut upacara Perayaan HUT RI } \\
\text { "17 Agustus" dan Gerak Jalan } \\
\text { Se Desa Wangun Jaya }\end{array}$ & & & & & \\
\hline 7 & Taman Baca & & & & & \\
\hline 8 & Senam Pagi & & & & & \\
\hline 9 & Seminar Hakikat Bahasa & & & & & \\
\hline 10 & PHBS di Paud & & & & & \\
\hline 11 & Pelatihan Pembuatan Telur Asin & & & & & \\
\hline 12 & Pelatihan Word & & & & & \\
\hline 13 & $\begin{array}{l}\text { Santunan ke Anak Yatim dan } \\
\text { Janda, dan Pelepasan mahasiswa } \\
\text { dengan warga setempat }\end{array}$ & & & & & \\
\hline 14 & $\begin{array}{l}\text { Pentingnya Surat dan Data } \\
\text { Administrasi Kependudukan. }\end{array}$ & & & & & \\
\hline
\end{tabular}




\section{Tahapan Pendekatan Sosial}

Untuk tercapainya pendekatan sosial yang baik, perlu dilakukan tahapan-tahapan pendekatan sosial, sebagai berikut:

\section{Pembukaan Hubungan}

Agar pelaksanaan KKN berjalan efektif dan efisien perlu dukungan dan partisipasi masyarakat. Oleh karena itu, mahasiswa dan dosen pembimbing perlu membuka hubungan dengan masyarakat. Dalam tahapan ini mahasiswa beserta dosen pembimbing dapat mengadakan diskusi atau loka-karya dengan semua pihak strategis di masyarakat tentang rencana kerja.

Selain terjadi saling memperkenalkan diri, dari pihak peserta KKN perlu pula memperkenalkan tentang pengertian, maksud dan tujuan Kuliah Kerja Nyata kepada masyarakat, sehingga masyarakat memperoleh pemahaman yang tepat dan memiliki kepedulian terhadap kegiatan KKN. Pada tahap ini perlu dibicarakan pula hal-hal teknis yang berkaitan dengan pelaksanaan KKN.

Selesai tahap ini, rencana atau program yang telah disiapkan sebelumnya perlu segera disesuaikan dengan berbagai perkembangan yang terjadi, sekaligus ditata dan dijajaki kemungkinan-kemungkinan realisasinya.

\section{Pemeliharaan Hubungan}

Hubungan yang telah terjalin melalui tahapan sebelumnya, selanjutnya perlu dipelihara dan dijaga agar suasana $\mathrm{KKN}$ tetap berjalan kondusif. Kehangatan dan keakraban serta saling percaya dengan masyarakat terus dipelihara melalui kegiatan komunikasi secara formal maupun informal. Dalam pemeliharaan hubungan, komunikasi informal dapat memberikan hasil yang jauh lebih efektif. Oleh karena itu, peserta KKN, baik secara individual maupun kelompok seyogyanya dapat mengembangkan komunikasi informal dengan seluruh lapisan masyarakat, misalnya pada saat di warung, shalat berjamaah di masjid atau dalam bentukbentuk kegiatan informal lainnya.

\section{Pembinaan Hubungan}

Pembinaan hubungan terutama dilaksanakan oleh pengelola KKN (lembaga atau tim yang ditunjuk oleh perguruan tinggi yang bersangkutan) pada saat mengadakan pemantauan (monitoring) dan evaluasi terhadap rencana dan pelaksanaan kegiatan yang telah disetujui pihak-pihak strategis. Pada tahap ini dapat terjalin hubungan kerja sama antara Perguruan Tinggi dengan masyarakat yang tidak hanya sebatas pada masa KKN, akan tetapi sangat dimungkinkan pula untuk menjalin kerja sama lanjutan yang mutualisme, setelah masa KKN berakhir. Pembinaan hubungan ini dimaksudkan untuk semakin memperkokoh hubungan kerjasama yang telah terjalin.

\section{Mengakhiri Hubungan}

Pada tahap ini peserta KKN berpamitan dengan masyarakat, baik secara formal maupun personal. Secara formal biasanya dilakukan secara seremonial dalam bentuk acara khusus pelepasan peserta KKN oleh masyarakat setempat. Dalam hal ini, perwakilan dari lembaga Perguruan Tinggi diharapkan dapat hadir, sekurang-kurangnya dihadiri oleh Dosen Pembimbing. Sedangkan secara personal, pamitan dilakukan antar-individu (interpersonal) dalam suasana yang tidak formal. Jika tidak memungkinkan untuk pamitan dengan seluruh masyarakat, paling tidak peserta KKN berpamitan dengan tokoh-tokoh masyarakat dan orang-orang 
yang telah berjasa memberikan bantuan dan dukungannya selama kegiatan $\mathrm{KKN}$ berlangsung.

Pengakhiran hubungan yang baik ditandai oleh adanya kesan positif dari kedua belah pihak. Kesan akhir positif hanya akan diperoleh manakala tahapan tahapan pendekatan sosial sebelumnya dapat dilalui dengan baik, yang disertai dengan karya-karya nyata yang dihasilkan selama kegiatan KKN berlangsung.

\section{REALISASI PROGRAM}

Berikut adalah capaian program yang dicanangkan melalui programprogram yang telah direncanakan:

\section{Bidang Pendidikan}

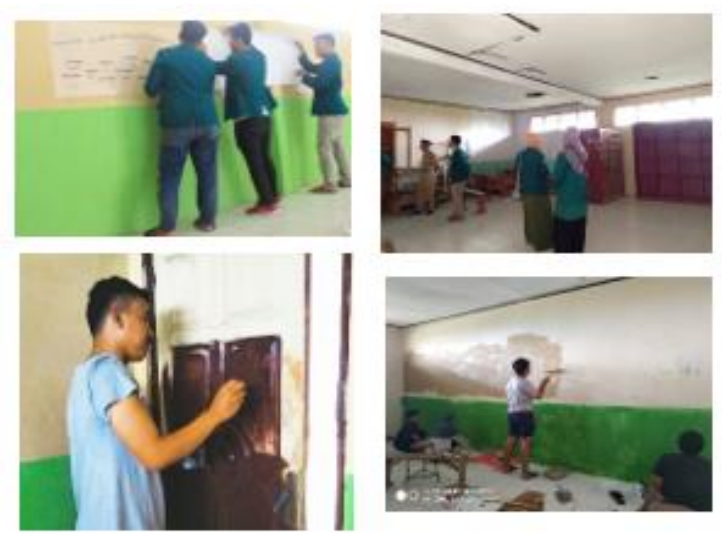

a. Mendekor Perpustakaan di MI PUI darul awwalin cisaranten 2

Dalam pengerjaan mendekor perpustakaan dimulai pada hari senin 20 Agustus 2018 sudah memulai mendekor oleh mahasiswa.


\section{b. Mengajar di Paud}

Pengajaran dilakukan di paud riyadhul jannah yang dilakukan pada hari kamis sampai jumat pada pukul 07.00 WIB sampai pukul 10.00 WIB.
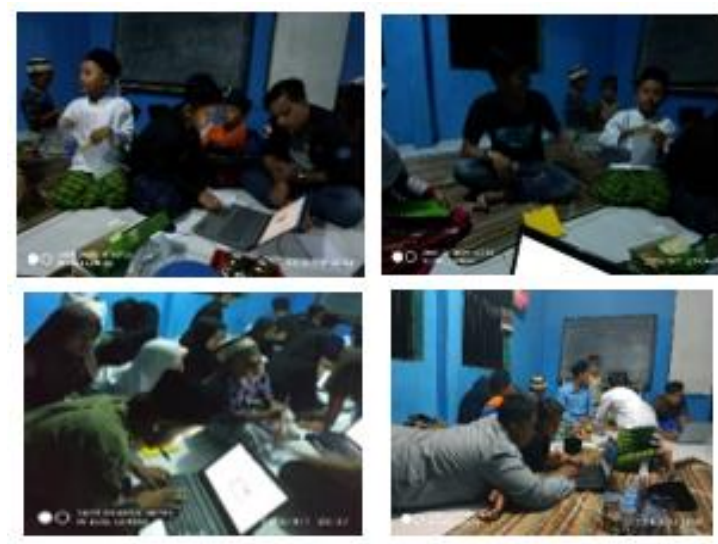

\section{c. Pembelajaran Ms Word}

Pembelajaran Ms Word ini dilakukan di Majelis Ta'lim Riyadhul Mubtadiin oleh mahasiswa dengan para santri, mengenal dan bagaimana cara menggunakan Ms Word ini dilaksanakan pada hari Jumat 31 Agustus 2018 s.d Minggu 02 Agustus 2018. 

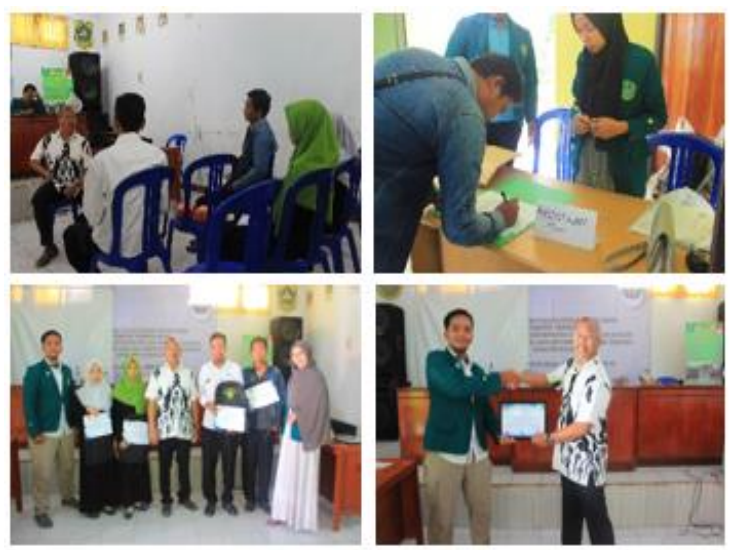

\section{d. Seminar Bahasa}

Seminar Bahasa ini di lakukan pada tanggal 29 Agustus 2018 di aula balai desa Wangun Jaya dengan jumlah pesrta sebanyak 4 orang terdiri dari guru MI PUI Darul Awwalin, SDN Cisaranten, SMPS An-Nuriyah. Membahas mengenai "Pentingnya Pengetahuan Hakikat Bahasa oleh Para Guru Bahasa".

\section{Bidang Agama}
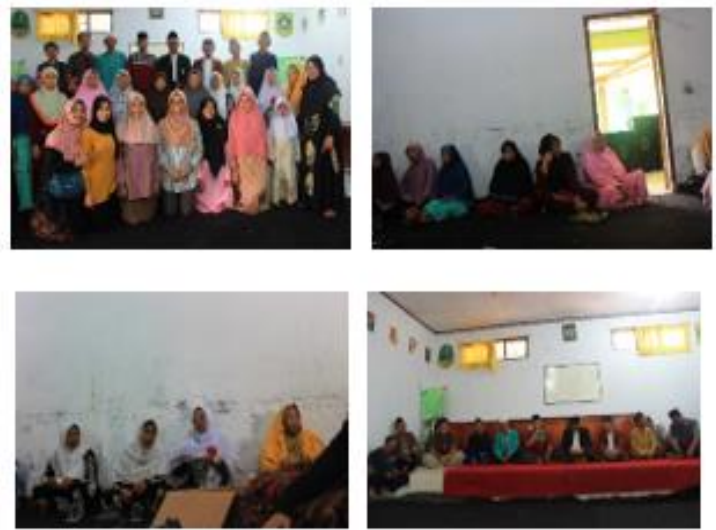

\section{a. Pengajian Majelis Ta'lim}

pengajian ini dilakukan dikantor Desa Wangun Jaya, yang bertujuan mendekatkan diri pada Tuhan Yang Maha Esa dan juga menjalin Talisiratuhrahmi ke masyarakat setempat.
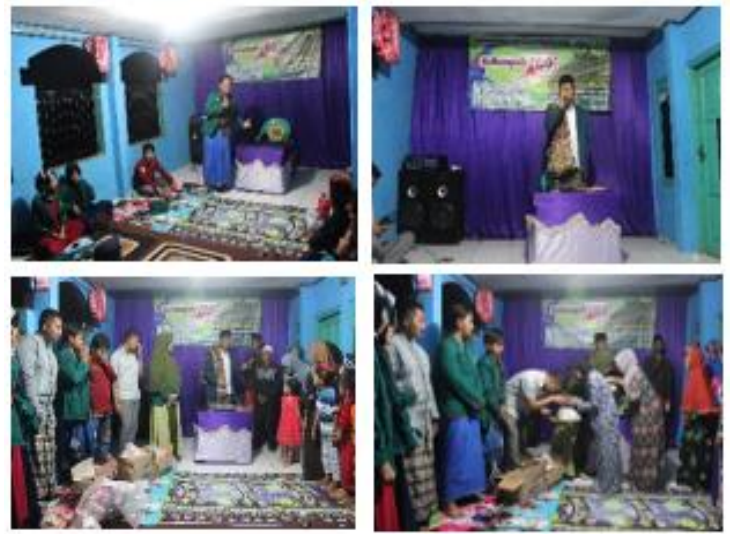

\section{b. Santunan dan Penutup}

Kegiatan santunan untuk Anak yatim dan juga Janda yang di laksanakan pada akhir. Sekaligus penutupan kegiatan KKN selama satu bulan dan juga berpamitan dengan warga setempat.

\section{Bidang Kesehatan}
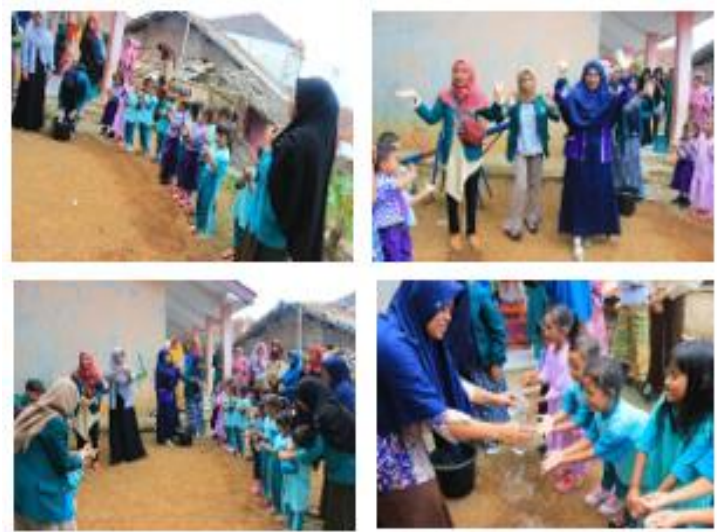

\section{a. Penyuluhan PHBS}

penyuluhan ini dilakukan di Paud agar mengedukasi mereka supaya hidup bersih dan sehat, ini dilakukan pada hari Kamis 30 Agustus 2018 oleh mahasiswan dengan siswa Paud. 

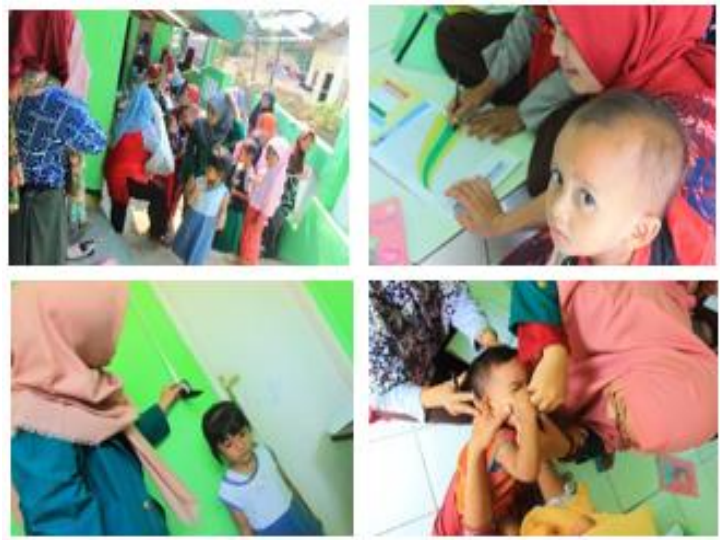

\section{b. Posyandu Belibis VIII}

Kegiatan posyandu bulannan di Desa Wangun Jaya yang di laksanakan pada tanggal 21-09-2018 di posyandu Belibis VIII yang mana kegiatannya yaitu penimbangan balita. Pengukuran tinggi kelak.

\section{Bidang Hukum}

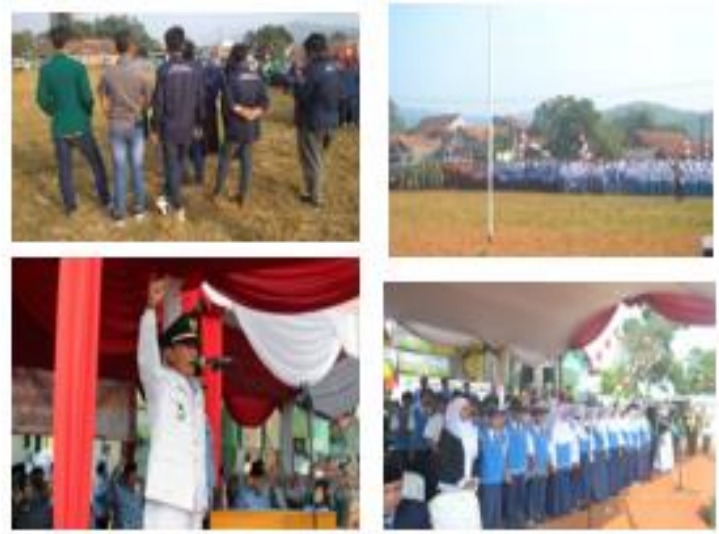

\section{a. Upacara HUT RI 73}

Upacara 17 Agustus tahun 2018 di laksanakan di lapangan desa Sibanteng kecamatan Leuwisadeng yang mana Perseta upacaranya dari pihak Pegawai Negeri Sipil, Organisasi Masyarakat, siswa-siswi PAUD, SD, SMP, SMA dan Mahasiswa Universitas Ibn Khaldun dan Mahasiswa Universitas Islam Negeri Syarif Hidayatullah pelaksanaan di mulai pukul 08.00 - 10.00 WIB.
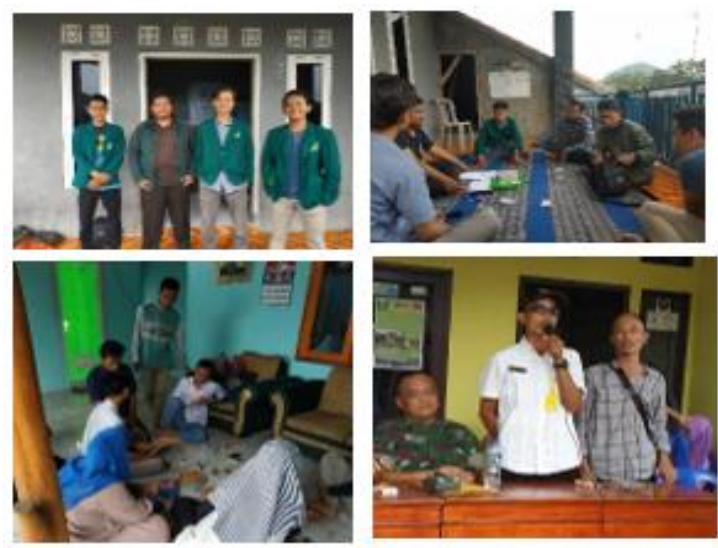

\section{b. Pentingnya Surat dan Data \\ Administrasi Kependudukan.}

Kamis, 30 Agustus 2018: Dengan sistem door to door datang ke rumah warga RW 08 Cisaranten II, untuk melakukan penyuluhan tentang pentingnya surat dan data administrasi kependudukan.

Maksud dari program ini adalah untuk membantu warga desa wangun jaya khususnya RW 08 Cisaranten II dalam mengetahui pengetahuan mengenai hukum dan pentingnya akta kelahiran, KTP dan Kartu Keluarga.

\section{Bidang Teknik}
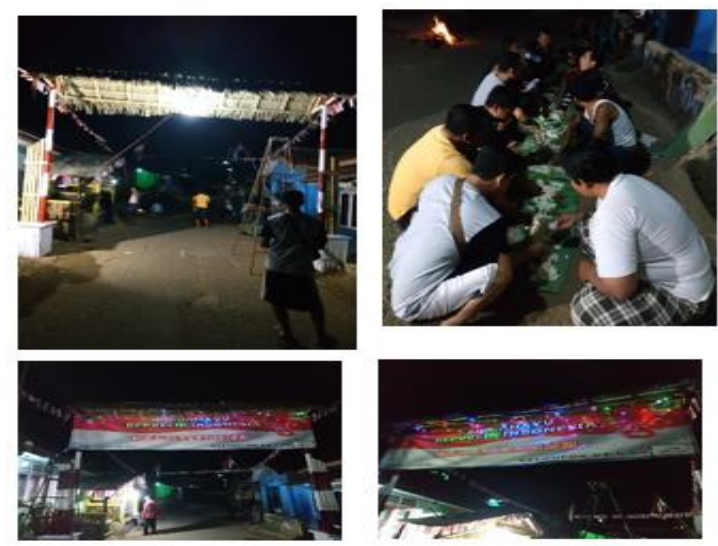

\section{a. Mendekor Gapura}

kegiatan ini pendekatan awal dengan masyarakat Kp. Cisaranten, dengan adanya gapura juga menyambut HUT RI 73 dan juga agar memperindah jalan masuk. 

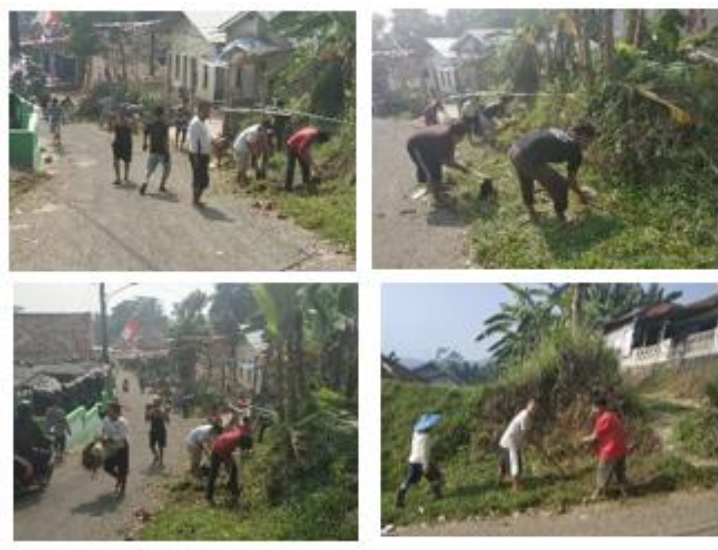

b. Gotong Royong

membersihkan sepanjang jalan menuju ke Kantor desa Wangun Jaya menyambut HUT RI 73 dengan masyarakat desa.

\section{Bidang ekonomi}
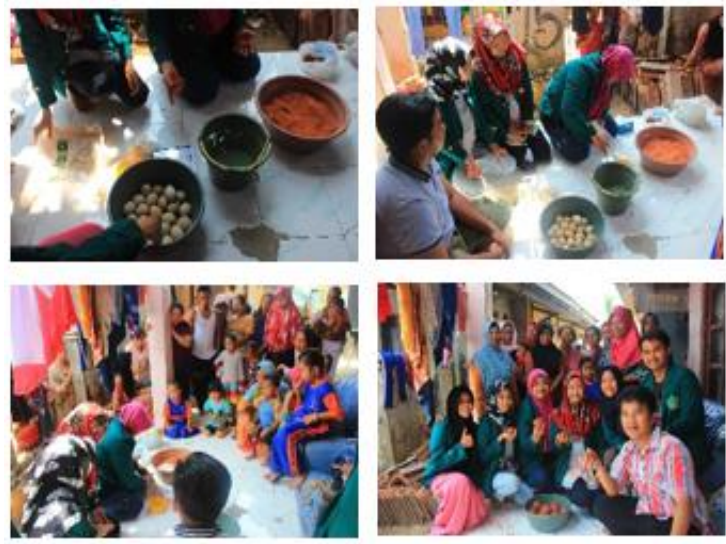

a. Pelatihan Pembuatan Telur Asin

pelatihan pembuatan telur asin ini dilakukan agar bisa membuka peluang bisnis dagang telur asin, ini diikuti banyak dari ibu-ibu setempat agar bisa memulai menjual telur asin, kegiatan ini dilaksakan pada hari sabtu 01 september 2018 di rumah warga.

\section{KESIMPULAN}

Kegiatan KKN dengan sasaran masyarakat Desa Wangun Jaya secara umum berjalan lancar sesuai apa yang di rencanakan. Meski target waktu yang di rencanakan tidak dapat sepenuhnya di jalankan sesuai dengan hal tersebut. Namun hal tersebut tidak merubah pelaksanaan program tersebut. Adapun kesimpulan dari pelaksanaan program kerja KKN di masyarakat Desa Wangun Jaya yang di laksanakan pada tanggal 7 agutus hingga 5 september 2018 yaitu :

1. Kerjasama antara anggota tim KKN kelompok 69 Desa Wagun Jaya sangat baik dalam pelaksanaan program.

2. Pihak aparat RT RW Tokoh agama Kampung Cisaranten 2 RW 08 yang sangat membantu kami dalam penyelesaian program kerja dan senantiasa memberi dukungan masukan pada anggota KKN 69 Desa Wangun Jaya.

3. Masyarakat Desa Wangun Jaya yang sangat mendukung adanya program KKN Desa Wangun jaya yang di laksanakan di desanya.

4. Kegiatan KKN di Desa Wangun Jaya mendapat sambutan yang baik dari masyarakat setempat yaitu dengan dukungan moril maupun materil demi kelancaran pelaksanaan kegiatan program KKN kelompok 69 Desa Wangun Jaya.

\section{SARAN}

Untuk pelaksanaan kegiatan $\mathrm{KKN}$ selanjutnya sebaiknya bantuan tenaga atau kesedian waktu dari pihak pemerintahan / aparat Desa untuk dapat di tingkatkan lagi karena di gunakan untuk mengembangkan potensi masyarakat Desa Wangun Jaya jika dukungan dari pihak pemerintahan atau aparat Desa tidak ada maka sia-sia bagi kami jika kami ingin mengembangkan potensi masyarakatnya jika tidak ada dukungan dari pihak aparat desa dan profesionalitas dalam bekerja. Sehingga program program yang telah kami buat setidaknya dapat di kembangkan untuk 
Volume 02 Nomor 04, Desember 2018

proses tindak lanjut dalam meningkatkan potensi masyarakat Desa Wangun Jaya.

\section{REFERENSI}

Dadang Iskandar, Dede Sukmana, Rahmah tullah.(2018) Meningkatkan kesadaran masyarakat akan pentingnya budaya literasi melalui berbagai media

Eska Perdana Prasetya (2017), Pemberdayaan Masyarakat Tentang Kesehatan, Pendidikan Dan Kreatifitas, Jurnal Abdi Dosen

Fatimah Fety, Latif Abdul, Salsabila Biella. (2018) Pengabdian masyarakat menuju desa pamegarsari yang mandiri melalui peningkatan pendidikan

(2017). Pedoman Pelaporan PPM UIKA 2017. Bogor. LPPM UIKA

(2018). Petunjuk Pelaksanaan KKN Tematik Terintegrasi 2018. Bogor; LPPM UIKA 